of officers at risk increased during our study; this probably reflects increases in urban violence and the number of drug abusers. Nevertheless, few officers had markers of hepatitis, which suggests that unreported exposure is uncommon.

A central service for the Metropolitan Police Force seems to work well; police officers and surgeons generally know the correct course of action after exposure, and prophylaxis can be given when it is most likely to be effective. An increasing problem is unavailability of blood from contacts, particularly drug abusers, who are often uncooperative and may have sclerosed veins; this may result in costly hepatitis B immunoglobulin being given unnecessarily. Vaccination of police officers would be effective in reducing the risk of acquiring hepatitis $B$ but would be expensive; at $£ 32.60$ per course it would cost over $£ 880000$ to vaccinate the 27000 officers in the Metropolitan police alone. The group most at risk is officers on ordinary street duty, some of whom have already been vaccinated by their general practitioners. Most officers can avoid contamination with hepatitis B by adopting precautions such as taking care with needles and wearing gloves when dealing with bleeding accident victims. For the others a service such as ours seems the most cost effective in preventing hepatitis $B$.

We thank the staff of PT5 Branch (Medical) of New Scotland Yard, in particular Miss Anne Peagam, executive officer, for their help in supplying some necessary details. We also thank Dr S Polakoff (Central Public Health Laboratory, Colindale) for sending us hepatitis B immunoglobulin.

1 Peterkin M, Crawford RJ. Hepatitis B vaccine for police forces? Lancet 1986;ii: 1458.

(Accepted 19 May 1988)

\section{Menstrual and ovulatory disturbance in bulimia}

\author{
Tim Cantopher, Chris Evans, J Hubert Lacey, \\ J Malcolm Pearce
}

\section{St George's Hospital Medical School, London} SW17 ORE

Tim Cantopher, MRCPSYCH, senior registrar in psychiatry Chris Evans, MB, research registrar in psychiatry J Hubert Lacey, FRCPSYCH reader in psychiatry J Malcolm Pearce, MRCOG, senior lecturer, fetal welfare laboratory

Correspondence to: $\mathrm{Dr}$ Lacey.

Anorexia nervosa is associated with menstrual disturbance. ${ }^{1}$ This is caused by hypothalamic dysfunction except when weight falls to below $70 \%$ of the mean pituitary function occurs. ${ }^{23}$ The cause of this hypothalamic-pituitary disturbance is not clear but a fall below a critical level of body fat is the most popular theory.

Women with bulimia at normal body weight have also been reported to suffer menstrual disturbance, but the cause is not known.

This preliminary study aimed at confirming this disturbance in women with bulimia, assessing the effect on ovulation, and investigating the underlying weight of a matched population, when disturbance of hormonal changes.

\section{Patients, methods and results}

Fourteen women aged 18 to 40 years who were within $10 \%$ of the mean weight of a matched population (taken from weight charts for a normal population) and were not taking the contraceptive pill entered the bulimic treatment programme during the study. The average age was 25 (range 16-46), mean weight $102 \%$ of the mean matched population weight (range $90-110 \%$ ). Binge eating and vomiting were reported on average five times a week (range 1-21 and 0-21 respectively) and mean duration of illness was five years (range 1-11). Of the sample, five women $(36 \%)$ had regular menses (cycles over the past six months not varying in duration by more than 10 days from one to the next), six ( $43 \%)$ irregular (at least one period in six months but cycles varying by more than 10 days), and three $(21 \%)$ absent (no periods in six months). The sample had a history of fairly stable recent weight, no patient having gained or lost more than $10 \%$ in weight during this time.

Three serum progesterone assays taken at two week intervals showed that two patients had ovulated and 10 had not, and two patients yielded equivocal results. Daily temperature charts showed that one of these last two (case 4) had ovulated during the study, while the other had not (case 10).

Of the $11(79 \%)$ patients who had not ovulated, three refused further investigation. The rest underwent a luteinising hormone releasing hormone stimulation test, entailing serial estimations of serum luteinising hormone and follicular stimulating hormone concentrations after intravenous injection of $100 \mu \mathrm{g}$ of luteinising hormone releasing hormone analogue. The results were interpreted according to the guidelines established by Bergh et al and Franks et al.${ }^{34}$ All eight patients also underwent an ultrasound scan of their ovaries (appearance classified according to the criteria of Adams ${ }^{4}$ ) and a progesterone challenge (menstrual type bleeding on withdrawal after five days of medroxy progesterone acetate $5 \mathrm{mg}$ daily indicates an endometrium primed by oestrogen).

Clinical details of 14 patients studied

\begin{tabular}{|c|c|c|c|c|}
\hline $\begin{array}{l}\text { Case } \\
\text { No }\end{array}$ & $\begin{array}{l}\text { Menstrual } \\
\text { pattern }\end{array}$ & Ovulation & $\begin{array}{c}\text { Ovarian } \\
\text { morphology }\end{array}$ & $\begin{array}{c}\text { Site of } \\
\text { dysfunction }\end{array}$ \\
\hline 1 & Amenorrhoea & No & Normal & Hypothalamus \\
\hline 2 & Irregular & No & & $\begin{array}{l}\text { Refused further } \\
\text { investigation }\end{array}$ \\
\hline 3 & Irregular & No & Not investigated & Pituitary \\
\hline 4 & Regular & Yes & & \\
\hline 5 & Regular & Yes & & \\
\hline 6 & Amenorrhoea & No & Polycystic & $\begin{array}{l}\text { Ovaries } \\
\quad \text { (polycystic) }\end{array}$ \\
\hline 7 & Irregular & No & Not investigated & Hypothalamus \\
\hline 8 & Regular & Yes & & \\
\hline 9 & Irregular & No & Multicystic & Pituitary \\
\hline 10 & Irregular & No & Normal & Hypothalamus \\
\hline 11 & Regular & No & Normal & Pituitary \\
\hline 12 & Amenorrhoea & No & Normal & Hypothalamus \\
\hline 13 & Regular & No & & $\begin{array}{l}\text { Refused further } \\
\text { investigation }\end{array}$ \\
\hline 14 & Irregular & No & & $\begin{array}{l}\text { Refused further } \\
\text { investigation }\end{array}$ \\
\hline
\end{tabular}

One patient (case 6) yielded a test result consistent with the presence of polycystic ovaries, which was confirmed by ultrasound. Three patients (cases 1, 7, 12) showed a pattern consistent with hypothalamic dysfunction (normal low baseline gonadotrophins with a pronounced response of luteinising hormone to stimulation). One (case 10) showed an intermediate response that we took to indicate hypothalamic dysfunction. Three patients (cases 3, 9, 11) showed a pattern consistent with pituitary dysfunction (poor response to luteinising hormone releasing hormone stimulation), and all three showed positive responses to progesterone challenge, indicating that lack of oestrogen priming was not the cause of the result. Prolactin concentrations were normal in all patients (table).

\section{Comment}

Nine (64\%) of our sample suffered menstrual irregularity or amenorrhoea and $11(79 \%)$ failed to ovulate 
during a six week period despite maintaining a stable weight. The cause of these disturbances seemed to be located at or above the level of the hypothalamus in four patients and the pituitary in three, and one patient had polycystic ovaries. No patients suffering pituitary dysfunction had a history of anorexia nervosa.

The ovarian ultrasound scan confirmed the test findings in all but one patient (case 11), in whom the pituitary disturbance may have been of insufficient duration to cause a change in ovarian morphology.

Though interpretation of the luteinising hormone releasing hormone test is not absolutely reliable, this study shows that anovulation and menstrual disturbance are common in women with bulimia of normal body weight and that anovulation is not associated with a consistent hormonal pattern. Possible causes of these disturbances include gross fluctuations in carbohydrate intake, disturbances of fluid and electrolyte balance caused by self induced vomiting and laxative abuse, or emesis leading to excessive dopaminergic brain activity.

Dr Evans received a grant from the Alcohol Education and Research Council. We thank Dr J Nesbitt and the chemical pathology department, St George's Hospital, for the hormonal assays and the Special Trustees of St George's Hospital for financial support.

1 Crisp AH, Stonehill E. Relation between aspects of nutritional disturbance and menstrual activity in primary anorexia nervosa. $\mathrm{Br}$ Med f 1971;iii: 149-51.

menstrual activity in primary anorexia nervosa. Br Med 1971 , in. 149 -s1. amenorrhoea. $\mathcal{f}$ Obstet Gynaecol Brit Commonwealth 1972;79:874-82.

3 Bergh T, Nillins SJ, Wide L. Serum prolactin and gonadotrophin levels before and after luteinising hormone releasing hormone in the investigation of amenorrhoea. Br J Obstet Gynaecol 1978;85:945-56.

4 Franks S, Adams J, Mason H, Polson D. Ovulatory disorder syndrome. Clin Obstet Gynaecol 1985;12:605-32.

(Accepted 8 June 1988)

\section{The closed eyes sign: an aid to diagnosing non-specific abdominal pain}

\section{Derek W R Gray, J Michael Dixon, Jack Collin}

Nuffield Department of Surgery, University of Oxford, John Radcliffe Hospital, Oxford OX39DU Derek W R Gray, FRCS, clinical lecturer J Michael Dixon, FRCS, registrar reader

Correspondence to: Mr Gray.
Jack Collin, FRCS, clinical

In $45 \%$ of patients attending hospital with acute abdominal pain no diagnosis is made ${ }^{1}$ and the term non-specific abdominal pain is used as a convenient diagnostic label. Probably patients with non-specific abdominal pain are in reality suffering from a wide range of conditions. Psychological factors may influence this pain or be the cause of it in some cases, and it would be helpful to be able to recognise physical signs pointing to a diagnosis of a psychosomatic condition. We noticed that patients with non-specific abdominal pain often keep their eyes closed during abdominal palpation whereas patients with organic disease usually keep their eyes open. Furthermore, the closed eyes are often associated with an expression inappropriate to a patient with pain. ${ }^{3}$ To test this observation we performed a prospective clinical study in patients admitted to hospital with abdominal pain.

\section{Patients, methods, and results}

We studied 158 consecutive patients complaining of abdominal pain admitted as an emergency to this department over six months. Patients with abdominal pain after trauma or recent surgery were excluded. The clinical details on admission were recorded on a standardised chart. During abdominal palpation the patient's eyes were carefully observed and the position of the eyelids recorded when abdominal tenderness were elicited. The findings were not used in subsequent management. After discharge from hospital all patients were seen at least once in the outpatient clinic, and the final diagnosis was recorded.

Of the 158 patients, 53 had a final diagnosis of appendicitis (median age 26 (range 11-89), male:female

Numbers of patients who closed their eyes during abdominal palpation

\begin{tabular}{lcccccccc}
\hline & \multicolumn{3}{c}{ No of patients observed } & & \multicolumn{3}{c}{ No (\%) who closed their eyes } \\
\cline { 2 - 3 } \multicolumn{1}{c}{ Diagnosis } & Total & Male & Female & & Total & Male & Female \\
\hline Appendicitis & 53 & 31 & 22 & & $2(4)$ & 2 & \\
Other disease & 38 & 20 & 18 & & $4(11)$ & & 4 \\
Non-specific abdominal pain & 67 & 25 & 42 & & $22(33)$ & 3 & 19
\end{tabular}

ratio of $1 \cdot 4: 1) ; 38$ had a variety of organic illnesses (median age 61 (17-88), male:female ratio $1 \cdot 1: 1$ ); and 67 had non-specific abdominal pain (median age 20 (11-75), male:female ratio $0 \cdot 6: 1$ ). Patients with appendicitis or non-specific abdominal pain were significantly younger than those with alternative diagnoses $(\mathrm{p}<0.06$, Mann-Whitney $U$ test), but there was no significant difference in age between patients with appendicitis and those with non-specific abdominal pain. The proportion of female patients was significantly higher among patients with non-specific abdominal pain than among those with appendicitis $\left(\chi^{2}=5.33, p<0.05\right)$. The table shows the proportions of patients who closed their eyes during abdominal palpation; the difference between the group with non-specific abdominal pain and the other groups was significant $\left(\chi^{2}=13 \cdot 1, \mathrm{p}<0.01\right)$. The predictive power of a positive result in the "closed eyes test" was 79\% and the predictive power of a negative result was $65 \%$.

\section{Comment}

Abdominal palpation to elicit tenderness is an unpleasant procedure endured by patients in the hope that it will help the doctor make a diagnosis. Voluntary guarding occurs when the patient sees the doctor's hand near the tender area. This phenomenon suggests that the natural reaction of a patient with genuine abdominal tenderness is to watch the doctor's hand carefully to avoid unnecessary pain. This eyes open response is to be expected in patients with abdominal tenderness secondary to organic disease. Our results showed that many patients with non-specific abdominal pain closed their eyes during abdominal palpation. One explanation for this is that they were aware (either consciously or unconsciously) that palpation would not produce severe pain, which implies that the pain had a psychological aetiology. There is some evidence that psychological causes contribute to non-specific abdominal pain. ${ }^{45} \mathrm{We}$ believe that this is the first description of a physical sign that may identify patients with non-specific abdominal pain due to psychological causes.

W Wilson DH, Wilson RG, Walmsley RG, Horrocks JC, DeDombal FT. Diagnosis of acute abdominal pain in the accident and emergency department. BrF S urg 1977;64:250-4

2 Gray DW, Collin J. Non-specific abdominal pain as a cause of acute admission to hospital. Br f Surg 1987;74:239-42.

3 Collin J, Gray DW. The eyes closed sign. Br Med f 1987;295:1656.

4 Ingram PW, Evans G. Right iliac fossa pain in young women. $\mathrm{Br}$ Med $\mathcal{J}$ 1965;ii: 149-51.

5 Joyce PR, Bushnell JA, Walshe JW, Moreton JB. Abnormal illness behaviou and anxiety in non-organic abdominal pain. Br f Psychiatry 1986;149:57-62. 